\title{
Sistema de monitoramento de energia Elétrica através da tecnologia do arduino.
}

\author{
Alessandro Vareiro Do Amaral', Denis Henrique de Deus Lima ${ }^{1}$, Sávio Vinícius \\ Albieri Barone Cantero ${ }^{1}$ \\ ${ }^{1}$ Instituto Federal de Mato Grosso do Sul (IFMS), Campus Ponta Porã - 79.900.000 - \\ Sanga Puitã - MS - Brasil \\ \{denis.lima, savio.cantero\}@ifms.edu.br, alessamdrooo@gmail.com
}

\begin{abstract}
The present work aims help people to have a better control of your expenses with electric power using a low-cost product. The energy consumption will be monitored in watts, to calculate how much energy is spending and what will be your value in the next reading. We will use the Arduino board, electronics prototyping platform, which will communicate with the sensor TCS-013-020 that is of type "non-invasive" and a web server where is stored the data and manage in real time which will contain information of value and rate of consumption of the next invoice. It is expected that there will be an awareness to reduce spending and preservation of nature.

Resumo. O presente trabalho tem com meta ajudar as pessoas ter um melhor controle de seus gastos com energia elétrica usando um produto de baixo custo. Será realizado o monitoramento do consumo de energia em watts para poder calcular quanto de energia está gastando e qual será o valor na próxima leitura do relógio. Será utilizada a placa Arduino, plataforma de prototipagem eletrônica, que se comunicará com o sensor não invasivo SCT013-020 e um servidor web aonde será armazenada os dados e os gerenciará em tempo real que vai conter informações do valor e indice de consumo da próxima fatura. Espera-se que haja uma conscientização quanto à redução dos gastos e preservação da natureza.
\end{abstract}

\section{Introdução}

O trabalho tem como objetivo desenvolver um sistema de monitoramento e cálculo do consumo de energia elétrica. O controle da energia gasta nas residências do Brasil vai afetar diretamente a economia, pois o consumidor terá consciência do que está consumindo e poderá reduzir os gastos. Além disso, ajuda na preservação da natureza, já que os recursos que utilizamos hoje em dia não são renováveis, um dia irão se esgotar [CUNHA, 2015].

Existem equipamentos no mercado que fazem o monitoramento e o cálculo de gastos com a energia elétrica, são conhecidos como Multimedidor ou Analisador elétrico e seus preços variam entre dois mil a três mil reais. A diante pode ser ver a Tabela 1 a comparação das características de especificações dos equipamentos. [FLUKE, 2016].

Neste trabalho utilizaremos a placa Arduino, open-source de protótipos eletrônicos baseados em hardware, de fácil uso, destinado a qualquer pessoa interessada 
em criar objetos ou ambientes. Serão conectados sensores não invasivos, ou seja, não necessita fazer nenhuma alteração na rede elétrica da residência.

A vantagem de se usar Arduino está no seu custo/benefício, por ser uma placa que possui vários recursos a um custo totalmente acessível [MCROBERTS, 2015].

\section{Metodologia}

Para o desenvolvimento do sistema de monitoramento, foram adquiridos os seguintes materiais: 1 Arduino UNO, 2 resistores de $10 \mathrm{~K} \Omega, 1$ capacitor de $100 \mathrm{uF}, 1$ Display LCD 16×2, 1 Potenciômetro de 10K, 1 sensor SCT-013-020 e um Shield Wifi (ESP8266). Equipamentos estes exibidos na Figura 1.

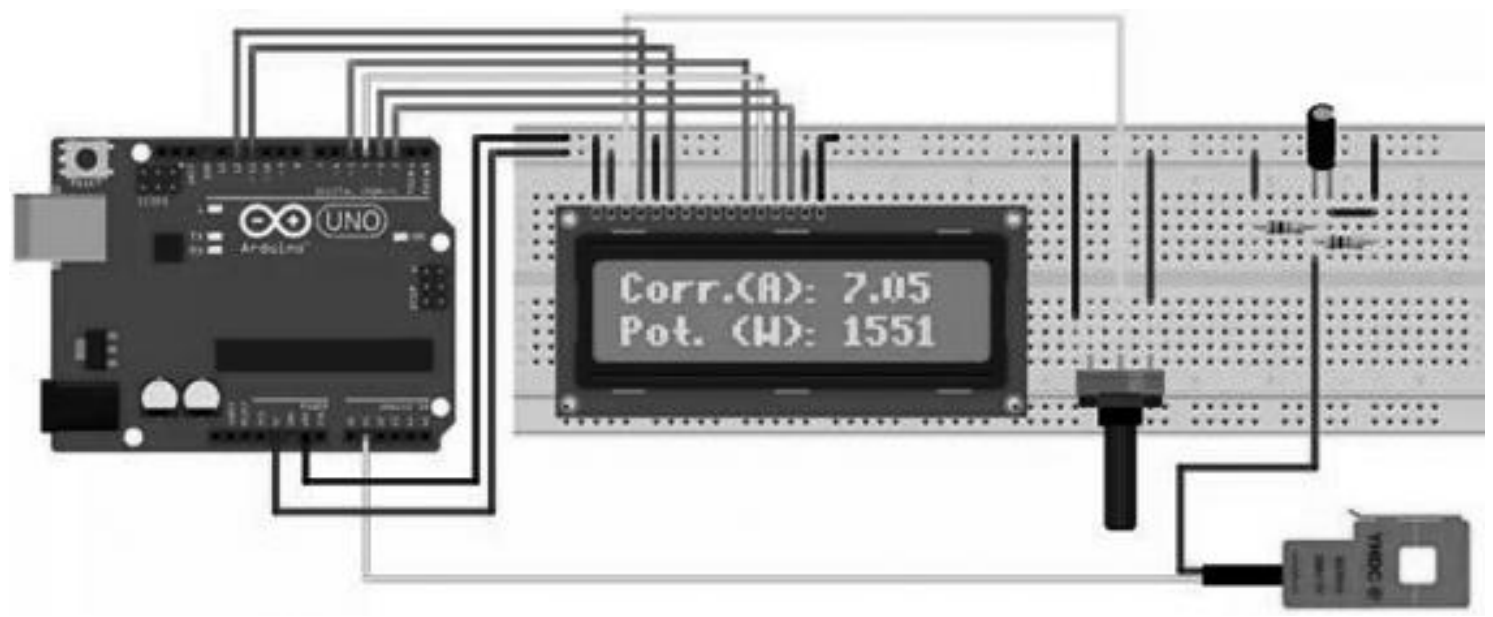

Figura 1 - Esquema de montagem do circuito do sistema.

O monitoramento da rede elétrica vai ser feito pela placa Arduino, para isso, o fio de energia - a ser monitorado - será envolvido de forma não invasiva pelo sensor SCT-013-020 que estará conectado esta placa.

Serão coletados dados como potência e intensidade e serão enviados utilizando o Wifi Shield-ESP8266 para a página via web, assim fazer monitoramento e coleta de dados em tempo real para ter uma melhor eficiência de fluxos de informações. E essas informações vai ser possível ser visualizada pelo usuário tanto em forma de valores estimando a conta da fatura de energia, como um gráfico com o índice de consumo por período que vai ser estipulado pelo o usuário. Esses dados visam promover tomadas de decisões para um melhor controle de gastos excessivos em paralelo à conscientização ambiental.

Para validação do protótipo titulado como EPA (Electric Power Analyzer), serão realizados testes em algumas redes domésticas. Após a validação, pretende-se implantar o sistema no mercado.

\section{Considerações Finais}

Esse sistema está sendo desenvolvido de forma modular para que novos componentes e outros sensores possam ser facilmente adicionados ao projeto, por exemplo: placa de rede e placa bluetooth. 
Este trabalho apresentou a proposta de um sistema de monitoramento da rede elétrica residencial de baixo custo como se pode observar a diante na tabela 1 a comparação dos equipamentos:

Tabela 1 - Comparação das características de especificações e preços dos equipamentos.

\begin{tabular}{|c|c|c|c|}
\hline & $\begin{array}{c}\text { Electric power } \\
\text { analyzer-EPA001 }\end{array}$ & $\begin{array}{l}\text { Multimedidor- } \\
\text { Dmi T50t88es }\end{array}$ & $\begin{array}{l}\text { Multimedidor- Kit } \\
\text { Dmi T5 1000a }\end{array}$ \\
\hline Especificações & Quantidade & Quantidade & Quantidade \\
\hline Placa de Comunicação & Sim & Sim & Sim \\
\hline $\begin{array}{l}\text { Sensor de Corrente não } \\
\text { invasivos } 100 \mathrm{~A} / 50 \mathrm{~mA}\end{array}$ & Sim & Sim & Não \\
\hline $\begin{array}{lcc}\text { Sensor } & \text { bipartidos } & \text { não } \\
\text { invasivos } & 1000 / 5 \mathrm{~A} & \\
\end{array}$ & Não & Não & Sim \\
\hline Pinos Digitais & Sim- 14 portas & Não & Não \\
\hline Entradas Digitais & Sim- 6 portas & Sim- 8 portas & Sim- 8 portas \\
\hline Saídas Digitais & Sim-6 portas & Sim-8 portas & Sim-8 portas \\
\hline $\begin{array}{l}\text { Conexão com a Internet Via } \\
\text { Wi-Fi }\end{array}$ & Sim & Não & Não \\
\hline $\begin{array}{l}\text { Conexão com a Internet Via } \\
\text { Cabo Físico }\end{array}$ & Não & Sim & Sim \\
\hline Fonte 12V 1a & Sim & Sim & Sim \\
\hline Sensor de Temperatura & Não & Sim & Sim \\
\hline Sistema de Interface Web & Sim & Sim & Sim \\
\hline Banco Da Dados em Nuvem & Sim & Não & Não \\
\hline $\begin{array}{l}\text { Banco De dados limitado de } \\
8 G B \text { ou } 32 G B\end{array}$ & Não & Sim & Sim \\
\hline Acesso Remoto & Sim & Sim & Sim \\
\hline Valor total & $R \$ 200,00$ & $\mathrm{R} \$ 1900,00$ & $R \$ 2200,00$ \\
\hline
\end{tabular}

Espera-se que com utilização do protótipo EPA haja um controle maior do consumo de energia elétrica por parte dos usuários, possibilitando uma maior economia doméstica, além de buscar a colaboração com a preservação do meio ambiente.

\section{Referências}

Cunha, J. (2015). "Desperdício consome $10 \%$ da energia elétrica no país, diz associação", http://wwwl.folha.uol.com.br/mercado/2015/02/1586778-desperdicioconsome-10-da-energia-eletrica-no-pais-diz-associacao.shtml, Fevereiro.

Fluke. (2016). http://www.fluke.com, Fevereiro.

Mcroberts, M. (2015). “Arduino Básico”. 2 a edição. São Paulo. Novatec. 